\title{
Children's Intuitive Teleology: Shifting the Focus of Evolution Education Research
}

\author{
Kostas Kampourakis • Eirini Palaiokrassa • \\ Maria Papadopoulou • Vasiliki Pavlidi • \\ Myrto Argyropoulou
}

Published online: 27 March 2012

(C) Springer Science+Business Media, LLC 2012

\section{Introduction}

Evolutionary theory is the central, unifying theory of biology. It explains the unity of life by documenting how extant and extinct species share a common ancestry. It also explains the diversity of life by describing how particular species have evolved from ancestral ones through natural processes. Charles Darwin laid the foundations of current evolutionary theory in 1859, in his book On the Origin of Species by Means of Natural Selection where he argued for the common ancestry of all life and proposed natural selection as the mechanism by which evolution proceeds (Darwin 1859). However, evolutionary biology has itself evolved since then as it incorporated advances in genetics, paleontology, and systematics (Huxley 1942), and later in other fields like developmental biology, molecular biology, and genomics (Pigliucci and Muller 2010). Evolution is currently considered a fact of life by scientists. An evolutionary perspective is dominant in many of the most active fields of biological research, such as comparative genomics and evolutionary developmental biology. Consequently, the teaching of evolution in biology courses provides students with a unifying, explanatory principle that organizes their understanding of life.

This notwithstanding, the idea of evolution has been debated enormously in the public domain. Various polls have shown that there is a low public understanding, and consequently acceptance, of evolution (see for example Miller et al. 2006). This low public acceptance is usually related to creationism (Intelligent Design being its most recent version - see Numbers 2006), and to the attempt to introduce an alternative, religiously founded, explanation for the origin of species in biology courses (Branch and Scott 2009). However, neither creationism nor Intelligent Design exhibits the necessary prerequisites for inclusion
K. Kampourakis $(\bowtie) \cdot$ E. Palaiokrassa $\cdot$ M. Papadopoulou $\cdot$ V. Pavlidi $\cdot$ M. Argyropoulou

Geitonas School,

P.O. Box 74128, Vari Attikis 16602, Greece

e-mail: kkamp@ath.forthnet.gr 
in the biology curriculum (Sober 2007; Audi 2009). Although creationism is certainly prevalent in the U.S. it is by no means only found there (Curry 2009; Graebsch and Schiermeier 2006; Hameed 2008; Numbers 2009).

However, resistance to evolution may not only be due to its perceived conflict with religious beliefs and personal worldviews. Resistance to scientific theories may be due to intuitions that arise in childhood and persist into adulthood, to generate preconceptions about the natural world and often make scientific findings seem unnatural and counterintuitive (Bloom and Weisberg 2007). It seems that particular preconceptions relevant to biology are never completely overwritten, despite significant understanding of biological processes or expert scientific knowledge (Goldberg and Thompson-Schill 2009). Some of the most usual preconceptions about evolution are related to teleology (for an overview and a developmental perspective see Evans 2008). Teleology is a mode of explanation in which a phenomenon is explained in terms of a final end or goal (telos) to which it contributes (Ariew 2007; Walsh 2008). In teleological explanations, a feature exists or a phenomenon is taking place in order to make something else possible. For example, the fact that birds have wings can be explained in teleological terms by their function: birds have wings for flying. Therefore, people who oppose evolution may not simply reject it because it conflicts with their religious beliefs and worldviews. Some (or many) of them may reject it because they do not understand it. In other words, the conflict may not only be between evolution and religious views but between evolution and teleological intuitions that make the theory of evolution seem counterintuitive.

Since evolution instruction in secondary and postsecondary education has been moderately effective (see Smith 2010 for a review), we suggest that evolution education research should focus on elementary science instruction. We believe that the study of elementary children's preconceptions, related to particular conceptual obstacles like teleology, may contribute to a better understanding of the resistance to the theory of evolution. In other words, secondary evolution instruction might be more effective if children's evolution-related preconceptions (like teleological ones) were diagnosed and addressed during elementary school. Rather than being viewed as an undesirable stage in their conceptual development, children's preconceptions actually are a necessary step (Carey 2000). If teachers neglect them, or are unaware of them because they are not always expressed, children's misunderstandings may become stronger as they grow up, despite the knowledge about

\footnotetext{
${ }^{1}$ Non-living natural objects are all objects that exist in nature which are not alive (contrary to organisms) and which have emerged through natural processes (and are not made by humans, as artifacts are). Rocks, and clouds are such non-living natural objects. Hereafter, we will refer to these simply as natural objects.
}

science they acquire at school. But contrary to other authors in this journal (Chanet and Lusignan 2009; Hermann 2011), we suggest that the problem is not whether and how evolution by natural selection should be taught in elementary schools. The main problem in understanding evolution is students' teleological intuitions (see González Galli and Meinardi 2011 in this journal). Thus, we studied young children's intuitive explanations for the features of organisms, artifacts, and non-living natural objects. ${ }^{1}$ Our research addresses the problem of resistance to evolution from a developmental-psychological perspective (not political) and with a focus on a different age group than usual (elementary rather than secondary or post-secondary).

\section{Theoretical Background}

Developmental evidence suggests that there are distinct stages in children's perception of evolution-related phenomena. It seems that five- to seven-year-olds tend to think that animals are eternal and unchanging, and that they cannot undergo radical changes during their lifetime. On the other hand, eight- to nine-year-olds are more likely to accept developmental and intra-species variation but are less likely than older children to accept common descent. They also realize that species are not eternal because at this age they begin to understand death. In addition, they tend to endorse creationist ideas. Finally, ten- to twelve-year-olds are more likely to accept the notion that one species may have descended from an entirely different one, and eventually to accept the idea of common descent for animals, but not always for humans (Evans 2008, p.281-282).

Explicit evolution instruction is usually taking place for the first time in secondary settings. Several studies in the past have documented that secondary students tend to intuitively provide teleological explanations for the existence of biological traits. It should be noted that in several of these studies, students' preconceptions have been characterized as Lamarckian, but this characterization does not adequately describe their (predominantly teleological) intuitive explanations (for an overview see Kampourakis and Zogza 2007). Moreover, few studies have examined students' teleological explanations in detail (Southerland et al. 2001; Kampourakis and Zogza 2008). Teleological explanations are not restricted to biology but may be given for chemical phenomena, as students may think that the behavior of a system is driven by intrinsic purposes (Talanquer 2007). For example, high school students may consider that atoms react in order to form molecules because they need to achieve a full outer shell to be a sufficient explanation for chemical reactions (Taber and Watts 1996). Similarly, physics high school students may believe that they can predict which of the objects would be hotter than the others by 
considering the basis of their intended use and not the properties of their structure (Harrison et al. 1999). In another study, children of four to five years old said that things fell because they had to, that the sun and moon did not fall because they had to give light, and that the clouds did not fall because they had to give rain (Bar et al. 1994).

Evidence from conceptual development research suggests that children tend to provide teleological explanations for the features of organisms and artifacts from very early in childhood (three to four years old). According to Keil, teleological explanations are given for organisms and artifacts. When children consider the natural world, they provide teleological explanations for the properties of organisms but not for natural objects, such as mountains. In a study, pre-school and second-grade children were shown either an emerald or a plant and were asked to choose between two explanations for the object's green appearance: a teleological explanation (e.g., they are green because it helps more of them to survive) and a physical explanation (e.g., they are green because tiny parts mix together to give them a green color). Both pre-school and second-grade children preferred teleological explanations for plants and physical explanations for emeralds (Keil 1992, p.129-130).

Keil has also suggested that although they tend to provide teleological explanations both for organisms and for artifacts, they are nevertheless able to distinguish organisms from artifacts due to two main differences between them. First, the properties of organisms serve the organisms themselves, whereas the properties of artifacts serve the purposes of the agents who use them. For example, roses have thorns to keep animals from getting at them, whereas barbed wire has barbs to prevent animals from accessing something valuable to humans. The second main difference is that organisms are perceived to have clearer essences than artifacts. This may stem from the fact that the way in which causal relations link properties together and explain their presence in organisms is clearer (Keil 1994, p.248-249). Hereafter, we will refer to this view, according to which teleology is used selectively for organisms and artifacts, as selective teleology.

On the other hand, according to Kelemen, teleological explanations are given for organisms, artifacts, and natural objects. Kelemen has suggested that the bias toward viewing objects as made for some purpose derives from an early sensitivity to intentional agents as object makers and users. Consequently, from the age of three to four years old children understand that agents act on the basis of goals and use objects in order to achieve them. This early awareness of intentional use of objects might influence children's explanations, particularly as most of the objects in their environment are artifacts, whose presence is explained by the way agents use them in order to achieve their own goals. Such experiences may eventually contribute to children's tendency to provide teleological explanations for all kinds of phenomena in the absence of other alternative explanations (Kelemen 1999a). In a study, four- and five-year-old children attributed functions not only to clocks and pockets, but also to non-living natural objects, such as mountains (for climbing) and clouds (for raining) as well as to organisms, such as babies (for loving) and to animals (for walking around), even though they were explicitly given the option of saying that they were not for anything (Kelemen 1999b). In another study, it was found that first-, second-, and fourth-grade children explained both animal properties, such as long necks, and non-biological natural properties, such as pointy rocks, in teleological terms (Kelemen 1999c). Hereafter, we will refer to this view, according to which teleology is used for organisms, artifacts, and natural objects as non-selective teleology.

More recent studies have not made clear whether children's teleology is selective or non-selective. For example, it has been suggested that five- and six-year-old children think that organisms, artifacts, and natural objects have functions. However, they perceive function as more central to artifacts than to natural entities (DiYanni and Kelemen 2005). On the other hand, it has been suggested that pre-school children clearly distinguish between organisms and artifacts, as they identify artifacts in terms of functions, while they identify animals in terms of appropriate biological characteristics (Greif et al. 2006).

Based on all the above, in our study we investigated preschool (five to six years old), first-grade (six to seven years old), and second-grade (seven to eight years old) children's teleological explanations for the features of organisms, artifacts, and natural objects. Our major research questions were the following:

- Are there any between-group and within-group differences in the number of teleological explanations for organisms, artifacts, and natural objects that preschool, first-grade, and second-grade children give?

- Do children provide more teleological explanations for the objects with which they are more familiar?

- Do children who provide teleological explanations explicitly correlate them with a perceived usefulness?

\section{Method}

The Research Instrument

In the studies of Keil and Kelemen discussed above, children most times had to choose between particular predetermined answers to the questions asked. We consider this a major limitation of these studies; not only because children 
were not free to express their own views, but also because the answers among which they had to choose might have influenced them in various ways, i.e., made them select those answers that seemed to be more "correct" and not the ones that were actually closer to their own views (if there were any). We believe that children should be facilitated to express their own views and be given the option not to provide any answer at all instead of being guided to select one answer out of a predetermined set. Thus, we developed a questionnaire which included open-ended questions only. The questions referred to three pairs of pictures shown to children featuring six items (two organisms, two artifacts, and two natural objects). In each pair, one item was familiar to children (duck, scissors and rock) and the other one was unfamiliar (booby, nutcracker, and stalagmite). The items were presented in the following order: duck, scissors, rock, booby, nutcracker, and stalagmite. Most importantly, children were explicitly told that there were no correct or wrong answers and they were also given the option to answer that they "do not know." We thus expected to document children's intuitive answers and explanations. To achieve this, we asked two distinct types of questions. These questions referred to artifacts and natural objects as wholes. Based on the conclusions from Greif et al. (2006), we asked these questions specifically for the feet of the two organisms, as students tend to provide teleological explanations not for whole organisms but for their parts.

The first type of questions served to document children's explanations, and to examine whether some of these were teleological. These questions had the form "Why does it have this feature?" and referred to the color and the shape of the feet of the duck and the booby, as well as to the color and the shape of the scissors, the nutcracker, the rock, and the stalagmite. These questions actually require causal explanations. Given that one can perceive three types of causes (ultimate, proximate, final) there are three possible types of explanations (evolutionary, proximate, teleological; for a more detailed analysis see Mayr 1961; Ariew 2003; Kampourakis and Zogza 2008). For example, the webbed feet of ducks can be explained in three different ways: (a) these ducks are descended from an ancestral species in which this feature (webbed feet) first emerged (ultimate or evolutionary explanation), (b) each foot has its shape because of particular genes which are expressed within the cells it consists of (proximate explanation), and (c) feet are webbed in order to facilitate ducks in swimming (teleological explanation). Although evolutionary explanations are the appropriate type of explanations to "Why?" questions (proximate explanations are answers to "How?" questions), teleological explanations are often given to "Why?" questions as well.

The second set of questions had the form "Is this feature useful for something?" and were used to let us conclude if teleological explanations were given by children in order to refer to a particular function or role or if they unconsciously used teleological language without having any function or role in mind. In other words, it was interesting to examine how many of those children who had provided teleological explanations, were really expressing their teleological intuitions and did not simply use expressions such as "in order to..." etc. A student who would provide an "in order to" explanation to a "Why?" question and then would describe why the respective feature was useful, would have explicitly expressed his/her teleological intuitions.

\section{Participants}

The study took place at a private school in Athens, Greece. According to Carey, important shifts in children's intuitive theories take place during the ages of five to seven (Carey 1985). The study involved 74 pre-school children (five to six years old), 153 first-grade children (six to seven years old) and 149 second-grade children (seven to eight years old). The pre-school children were divided into five classes of approximately 15 children. The first and the second graders were divided into six classes (for each grade) of approximately 25 children. The study was designed to be part of a regular course on Natural Sciences taught in all grades which is included in the national curriculum.

\section{Data Collection}

The study was conducted separately for each group. The pre-school study lasted from February to May 2010, the first-grade study lasted from February to March 2010 and the second-grade study was completed within four days during March 2010. The data collection process differed in the pre-school group from the first-grade and the secondgrade groups. The pre-school research protocol was the following: Each child was separately interviewed by a tester and a scorer. We decided not to audiotape children's answers as we were afraid that the audio-recorder would make them feel nervous. Thus, the tester performed the interview and kept notes, while the scorer also kept back up notes of students' answers. The average duration of the interviews, which took place in the children's classroom during the regular class period with their nursery teacher, was 15 minutes. Each interview begun with the following statement by the tester "We are going to play a game. At the beginning, we will show you some pictures and then we will ask you questions about these pictures. You will probably not be familiar with all of the objects depicted on the pictures. You are not supposed to know the answers to all questions, so the answer 'I don't know' is acceptable. Please feel free to share with us everything that comes in your 
mind." The interview consisted of open-ended questions about the six items. The pictures of the items were shown to children on A3 printouts. The pictures of the familiar items (duck, scissors, and rock) were shown first, followed by those of the unfamiliar ones (booby, nutcracker, and stalagmite). We refrained from presenting the members of the same pair consecutively (e.g., the booby right after the duck) to children because we did not want them to provide the same type of explanation just because the consecutive objects had some similarities.

The research protocol followed for the first-grade and the second-grade groups was the following: a researcher and the teacher of each class collected the data. The same researcher was present in all classes of the same grade (six first-grade classes and six second-grade classes). Teachers were present during the data collection because we wanted children to feel comfortable and not to be anxious that they were being assessed by unfamiliar people. Children were not interviewed as in the preschool group. Being able to write, they were given a printout of the questionnaire. All children were given the same handouts, consisting of a six-page pack of black-and-white copies. Each page contained questions for a particular item. The pictures used during the interviews of the preschool group, were also used for the first- and second-grade groups and they were presented in the same order. The items were shown to children on two identical A3 printouts; one was attached on the blackboard and the other was brought to children upon request. Children were asked to have a look at the printouts and then to silently write down the answers to all questions. No further instructions were given to children, apart from the initial ones which were the following: "You will be asked questions about organisms, artifacts and natural objects. We will show you some pictures and you will have to answer the questions included in the questionnaire. You are not supposed to know the answers to all questions. This is not a formal assessment; you will not get any credit for this. This is simply a process of collecting your thoughts, so please feel free to write down your thoughts and beliefs and do not hesitate to write that you do not know the answer to a question." Then children were given time to complete the questionnaire. The whole process of data collection varied in time. First-grade children completed the questionnaire within four class periods (45 minutes each), whereas second-grade children completed it within one class period.

We should note at this point that we are aware of the limitations of using a pencil-and-paper questionnaire with first-grade and second-grade groups. Studies with children of this age are usually performed with interviews. These certainly allow for a more detailed documentation of students' explanations and a deeper understanding of their thoughts, compared to the written questionnaire. However, by using written questionnaires, we managed to collect data from 153 first-grade children within a month and from 149 second-grade children within four days. This ensured that all children had been taught pretty much the same topics and concepts when they completed the questionnaires and that any differences observed would not be due to different content knowledge. We also consider the fact that these children were indeed able to complete the six-page questionnaire an interesting finding itself.

\section{Data Analysis}

Children's explanations for the first type of questions ("Why does it have this color/shape?") were coded as teleological or non-teleological; the second type of questions ("Is this color/shape useful for something?") were coded as useful or other. All children's explanations were independently coded by at least two researchers until absolute agreement was achieved. All statistical tests were performed by SPPS 16 . To investigate whether children of different grades provided different numbers of teleological explanations we first conducted a one-way analysis of variance (ANOVA), to compare the mean number of teleological explanations (for all objects, both for color and shape) between the three groups. Then we conducted a multivariate ANOVA to compare the mean number of teleological explanations (both for color and shape) separately for each item type shown to children between the three groups - a three (grade: K, first grade, second grade) by three (object type: organisms vs. artifacts vs. non-living natural objects) ANOVA. Finally, we conducted independent McNemar tests to compare children's answers within each of the three groups. In particular, we compared the teleological explanations for each item and for each of its features (color/shape) for particular item pairs, as well as teleological explanations with explanations for usefulness for each item.

\section{Results $^{2}$}

“Why?" Questions and Teleological Explanations

Children's explanations for the first question ("Why does it have this color/shape?") were coded as teleological or nonteleological. Children of all groups provided teleological explanations for the color and shape of organisms' feet, artifacts, and natural objects. Some children did not provide any explanation, as they were told they could do. This was done in order to make sure that children would express their

\footnotetext{
${ }^{2}$ In this article, we present an overview and comparison of the results for all grades (K-2) and we suggest a program for further research. The results of our study of second grade students are presented in detail in Kampourakis et al. 2011.
} 
Table 1 Percentage (\%) of children who provided teleological explanations

\begin{tabular}{|c|c|c|c|c|}
\hline \multicolumn{2}{|c|}{$\begin{array}{l}\text { Percentage }(\%) \text { of children } \\
\text { who provided teleological } \\
\text { explanations }\end{array}$} & \multirow{2}{*}{$\begin{array}{l}\text { Pre-school } \\
(N=74) \\
20.3\end{array}$} & \multirow{2}{*}{$\begin{array}{l}\text { First-grade } \\
(N=153) \\
9.2\end{array}$} & \multirow{2}{*}{$\begin{array}{l}\begin{array}{l}\text { Second-grade } \\
(N=149)\end{array} \\
4.7\end{array}$} \\
\hline Duck feet & Color & & & \\
\hline & Shape & 40.5 & 45.8 & 38.9 \\
\hline \multirow[t]{2}{*}{ Scissors } & Color & 17.6 & 5.2 & 9.4 \\
\hline & Shape & 63.5 & 56.2 & 52.4 \\
\hline \multirow[t]{2}{*}{ Rock } & Color & 18.9 & 8.5 & 4.0 \\
\hline & Shape & 20.3 & 11.8 & 5.4 \\
\hline \multirow[t]{2}{*}{ Booby feet } & Color & 16.2 & 13.1 & 8.7 \\
\hline & Shape & 32.4 & 38.6 & 33.6 \\
\hline \multirow[t]{2}{*}{ Nutcracker } & Color & 12.2 & 4.6 & 7.4 \\
\hline & Shape & 29.7 & 35.3 & 36.2 \\
\hline \multirow[t]{2}{*}{ Stalagmite } & Color & 16.2 & 5.2 & 4.7 \\
\hline & Shape & 13.5 & 10.5 & 4.7 \\
\hline
\end{tabular}

intuitions freely and that they would not give an explanation just because they had to. What is interesting is that teleological explanations predominated among the explanations given by children; however, in our analysis we included the "do not know" answers in the group of non-teleological explanations. The percentages of children's teleological explanations in each group are presented in Table 1.

Table 1 shows something like a shift from a non-selective teleology to a more selective one. While many children of all grades provided teleological explanations for the shape of organisms' feet and for the shape of artifacts, there is a decline in the number of children who did the same for the respective colors from the pre-school towards the secondgrade group. In other words, while there is a clear pattern of selective teleology for the shapes in the second-grade group, there is no such pattern in the pre-school group, as they provided many teleological explanations for the colors of the items as well. To investigate if there is a statistically significant difference in the number of teleological explanations between the three groups, we conducted a one-way ANOVA in order to compare the mean number of teleological explanations in each group.

The one-way ANOVA found statistically significant differences in the mean number of teleological explanations (for all items, both for color and shape) between the three groups, $F(2,180)=3.175, p<0.044$. The post hoc analysis indicated a statistically significant difference between the preschool and the second-grade groups $(p<0.014)$ but not between any of these two groups and the first-grade group. This result suggests a gradual decrease of the mean number of teleological explanations from preschool to second grade, as shown in Fig. 1. This is an interesting finding and suggests that children's grade (and consequently their age) may affect the number of teleological explanations they give: the older the children, the less the mean number of teleological explanations they give.

Given this finding, it was important to investigate what made this difference between the three groups. Did secondgrade children give teleological explanations in the same way for all test items (organisms, artifacts, natural objects) or for some of them more than others? To investigate this, we conducted a three-by-three ANOVA (grade $\times$ item type) both for the color and for the shape of the different items. We found statistically significant differences in the mean number of teleological explanations between the three groups only for natural objects but not for organisms and artifacts. The post hoc tests showed that there was a statistically significant difference in the mean number of teleological explanations for the natural objects between the preschool group and the second-grade group $(p<0.001)$ but not between any of these two groups and the firstgrade group. These findings suggest that the difference in the mean number of teleological explanations for all items between the preschool group and the second-grade group found in the one-way ANOVA was actually due to the difference in the mean number of teleological explanations given for natural objects (Fig. 2). These results are very important because what seems to decrease with age is the number of children who provide teleological explanations for natural objects. This stands as evidence for a shift from non-selective to selective teleology.

In order to examine whether the items selected for the study had a particular effect on children's teleological explanations, we conducted McNemar tests for each pair of items (feet of organisms, artifacts, and natural objects), for each feature separately. For example, we investigated if there was a statistically significant difference between the number of teleological explanations that the children of each group gave for the color of the scissors and the color of the 
Fig. 1 Mean number of teleological explanations for each grade

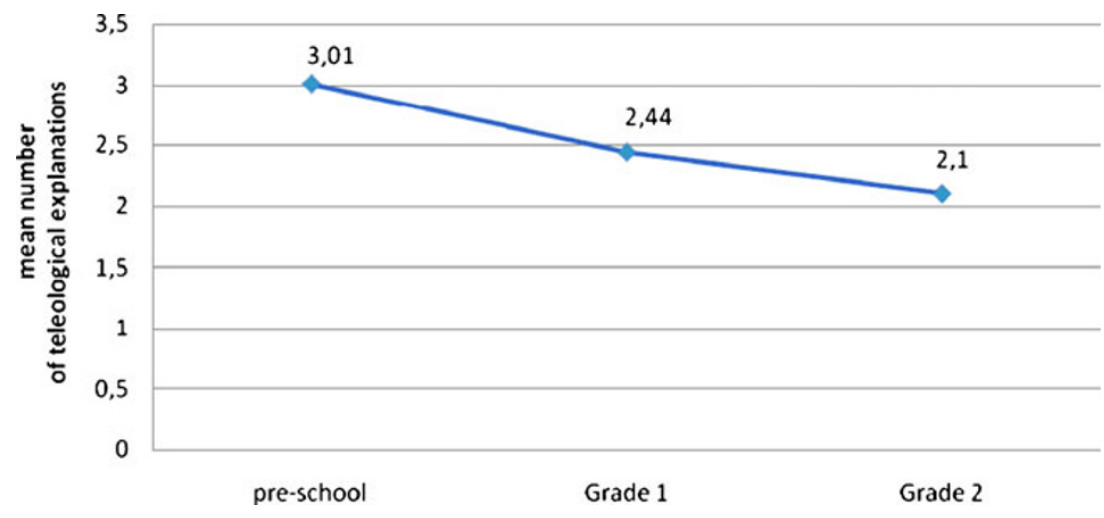

nutcracker (similarly we examined duck feet color vs. booby feet color, duck feet shape vs. booby feet shape etc.). In all comparisons, differences were statistically non-significant except from one: There was a statistically significant difference $(p<0.001)$ in all three groups between the number of teleological explanations for the shape of the scissors and the shape of the nutcracker. In this case, the item shown to children had an effect; a possible explanation for this difference is that children were very familiar with the use of scissors and as a result, many of them provided teleological explanations for it. On the contrary, although many children realized that the nutcracker is a tool, and that its shape must have been intentionally designed for some use, this was not as obvious as the use of the scissors was, and consequently fewer children provided teleological explanations for the nutcracker than for the scissors, which resulted in a statistically significant difference.

Teleological Explanations and Explanations for Usefulness

The second question of the questionnaire ("Is this feature useful for something?") was included in order to distinguish between: a) those children who gave teleological explanations because they had in mind a particular use of the features under question and b) those who did so without a clear conception of what the particular features were for. An interesting finding is that although many children provided both teleological explanations and explanations for usefulness for the shape of particular items, there was not always a correlation between these two types of explanations (Table 2).

Interestingly enough, there was a correlation between teleological explanations and explanations for usefulness for the shape of the nutcracker (with which most children were unfamiliar), but not for the shape of the scissors (with which most children were familiar). Given that one would expect quite the contrary result, we conclude that perhaps the concept of "usefulness" was not clear to all children. If we focus on children's explanations for the shape of the feet of the duck and the booby and for the shape of the scissors and of the nutcracker, we find that there were differences between the three groups. In particular, $16.3 \%$ of preschool children provided both types of explanation for the shape of the feet of the duck with a correlation between the two types, but $28.4 \%$ of them provided both types of explanation for the shape of the scissors without a correlation between the two types. Given that in all other cases (shape of the feet of the booby and shape of the nutcracker) less than $10 \%$ of pre-school children provided both types of explanation, one might question whether these children actually understood the question about usefulness.
Fig. 2 Mean numbers of teleological explanations per item type for each grade

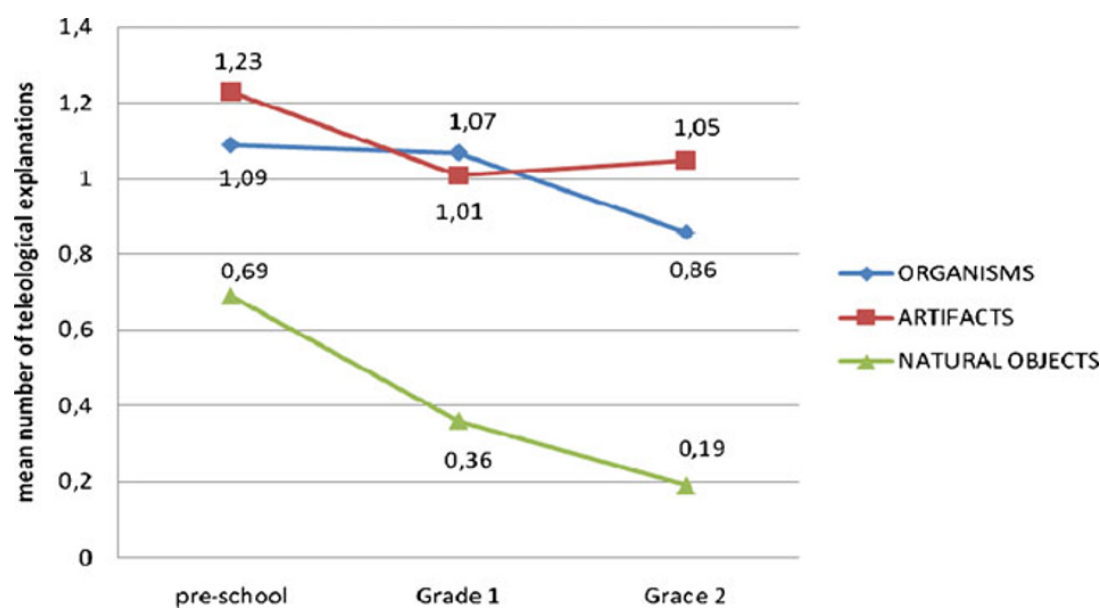


Table 2 Percentage (\%) of children who provided both teleological explanations and explanations for usefulness
${ }^{a}$ Indicates that there was no statistically significant difference and that therefore there was a correlation between teleological explanations and explanations for usefulness

\begin{tabular}{|c|c|c|c|c|}
\hline \multicolumn{2}{|c|}{$\begin{array}{l}\text { Percentage }(\%) \text { of children who } \\
\text { provided both teleological explanations } \\
\text { and explanations for usefulness }\end{array}$} & \multirow{2}{*}{$\begin{array}{l}\begin{array}{l}\text { Pre-school } \\
(N=74)\end{array} \\
2,7^{\mathrm{a}}\end{array}$} & \multirow{2}{*}{$\begin{array}{l}\text { First-grade } \\
(N=153) \\
5.8\end{array}$} & \multirow{2}{*}{$\begin{array}{l}\text { Second-grade } \\
(N=149) \\
1.3^{\mathrm{a}}\end{array}$} \\
\hline Duck feet & Color & & & \\
\hline & Shape & $16.3^{\mathrm{a}}$ & $31.4^{\mathrm{a}}$ & $17.4^{\mathrm{a}}$ \\
\hline \multirow[t]{2}{*}{ Scissors } & Color & $1.4^{\mathrm{a}}$ & $0.7^{\mathrm{a}}$ & $0.7^{\mathrm{a}}$ \\
\hline & Shape & 28.4 & 37.3 & $29.5^{\mathrm{a}}$ \\
\hline \multirow[t]{2}{*}{ Rock } & Color & 5.4 & $3.3^{\mathrm{a}}$ & $2.7^{\mathrm{a}}$ \\
\hline & Shape & 4.1 & $3.9^{\mathrm{a}}$ & $1.3^{\mathrm{a}}$ \\
\hline \multirow[t]{2}{*}{ Booby feet } & Color & $4.1^{\mathrm{a}}$ & $5.3^{\mathrm{a}}$ & $4.0^{\mathrm{a}}$ \\
\hline & Shape & 8.1 & 21.6 & $18.1^{\mathrm{a}}$ \\
\hline \multirow[t]{2}{*}{ Nutcracker } & Color & 2.7 & $2.6^{\mathrm{a}}$ & $1.3^{\mathrm{a}}$ \\
\hline & Shape & $6.8^{\mathrm{a}}$ & $26.1^{\mathrm{a}}$ & $22.2^{\mathrm{a}}$ \\
\hline \multirow[t]{2}{*}{ Stalagmite } & Color & $5.4^{\mathrm{a}}$ & $1.3^{\mathrm{a}}$ & $1.3^{\mathrm{a}}$ \\
\hline & Shape & $1.4^{\mathrm{a}}$ & $7.2^{\mathrm{a}}$ & $2.0^{\mathrm{a}}$ \\
\hline
\end{tabular}

Similar (and perhaps even stranger) are the results for firstgrade children. On one hand, $31.43 \%$ of first-grade children provided both types of explanation for the shape of the feet of the duck and $26.1 \%$ of them provided both types of explanation for the shape of the nutcracker, with a correlation between the two types. On the other hand, $37.3 \%$ of them provided both types of explanation for the shape of the scissors and $21.6 \%$ of them provided both types of explanation for the shape of the feet of the booby, without a correlation between the two types. In short, one can hardly accept that preschool and first-grade children understood what usefulness means and yet did not find the shape of the scissors useful. Only second-grade children provided both types of explanation for the shape of the feet of the duck and of the booby, as well as for the shape of the scissors and the nutcracker with a correlation between the two types in each of these cases. Some representative examples of students' explanations from all three grades are presented in Table 3.

\section{Conclusions and Suggestions for Further Research}

Conceptual change in children's naive biology has been studied over the years. Biological thinking emerges as an autonomous domain of theorizing during childhood, although a disagreement exists on how autonomous it is (Carey 1985; Keil 1992; Springer 1999). This conceptual change seems to consist of spontaneous conceptual change, which takes place during development due to maturity and independently of any instruction, and instruction-based conceptual change, that is due to particular teaching interventions that aim at promoting conceptual change. It is difficult to distinguish between these two types of conceptual change during elementary school, and whatever is happening is probably the outcome of both maturity and schooling (Inagaki and Hatano 2002, p.153-154). However, in the case of intuitive teleology such a distinction may be possible, not only because elementary instruction does not explicitly
Table 3 Examples of students' teleological explanations

\begin{tabular}{|c|c|c|c|}
\hline & & Teleological explanations & Explanations for usefulness \\
\hline \multirow[t]{2}{*}{ Duck feet } & Color & In order to swim fast & For concealment \\
\hline & Shape & In order to swim & In order to swim well \\
\hline \multirow[t]{2}{*}{ Scissors } & Color & In order to show that it is sharp & In order to cut things \\
\hline & Shape & In order to cut & Because humans like it that way \\
\hline \multirow[t]{2}{*}{ Rock } & Color & So that lizards can conceal themselves & In order to look nice \\
\hline & Shape & So that humans can sit on it & In order to look heavy \\
\hline \multirow[t]{2}{*}{ Booby feet } & Color & In order to be indistinguishable in the water & So that its feet are more beautiful \\
\hline & Shape & In order to swim & In order to swim well \\
\hline \multirow[t]{2}{*}{ Nutcracker } & Color & In order to look nicer & In order to be different \\
\hline & Shape & In order to break nuts & So that people break things \\
\hline \multirow[t]{2}{*}{ Stalagmite } & Color & In order to be beautiful & Because it looks nice \\
\hline & Shape & In order to look nice & So that the cave will look nicer \\
\hline
\end{tabular}


address children's teleological intuitions and preconceptions, but also because children are often implicitly driven to an enhancement of these intuitions. For example, many popular wildlife and nature programs seem to present evolution in teleological terms, because they often present organisms as perfectly designed in order to survive (Aldridge and Dingwall 2003). Consequently, children are not expected to undergo any spontaneous conceptual change from teleological to non-teleological intuitions, as even adults tend to intuitively provide teleological explanations as well (e.g., Kelemen and Rosset 2009).

Our results indicate a conceptual shift from non-selective to selective teleology during the ages of five to seven years old. Of course, these results are not conclusive; a longitudinal study would be required to confirm such a shift. Overall, it seems that pre-school children apply teleology in a nonselective manner. This does not only have to do with the item type (organism, artifact, or natural object), but also with the particular feature explained (color or shape). On one hand, pre-school children provided teleological explanations for all item types (though more for organisms and artifacts), both for the color and for the shape (though more for the shape). On the other hand, second-grade children provided less teleological explanations, mostly for organisms and artifacts and mostly for the shape. The number of teleological explanations of the first-grade children was intermediate between those of the pre-school and the second-grade group children. These results suggest that there may be a shift in how selectively teleological explanations are applied during the ages five to seven years old.

The results of our study suggest that both Keil and Kelemen could have made correct conclusions for particular ages, if Kelemen's studies had mostly involved preschool children (four to five years old) exhibiting a less selective teleology, and if Keil's studies had mostly involved older children (six to seven years old) exhibiting a selective teleology. However, this was not the case; both researchers included children of various ages in their studies. In what follows, we propose a research program that might contribute to a better understanding of children's teleological intuitions and of how these might change during development. The proposed research program has the following objectives: (1) to document students' teleological explanations and analyze the preconceptions on which they are based, (2) to study whether these preconceptions and the intuitions that generate them change during the normal course of development, and (3) to investigate whether particular interventions can challenge these preconceptions and promote conceptual change.

No longitudinal study has ever been performed in order to study children's teleological explanations. Thus, a developmental view can so far only be inferred by accumulating the conclusions of independent bodies of research (e.g.,
Evans 2008). In order to provide an in-depth analysis of elementary students' teleological intuitions from a developmental perspective, we suggest that a four-year longitudinal study is necessary (kindergarten to grade three; grade one to grade four; grade two to grade five; grade three to grade six). A proposed research design is summarized in Table 4. All tests (pre-tests, intermediate tests, post-tests) should be performed with semi-structured interviews.

As already discussed above, studies with preschool and elementary children have shown that they tend to provide teleological explanations for the features of organisms and artifacts, and in some cases of natural objects, from a very early age (three to four years old). Two distinct bodies of research, by Keil and Kelemen, have led to different results and conclusions about children's teleological intuitions. The first aim of the proposed research is to clarify whether teleology is applied selectively for organisms and artifacts, or if it is generally applied to (non-living) natural objects as well. We anticipate that the pre-tests which will be performed in year one of the proposed study will provide evidence in support of one of the two competing theories about the type of children's teleological intuitions (selective or non-selective). For this purpose, all pre-tests will include two types of questions that will explicitly ask students why some organisms, artifacts, and natural objects have particular features, whether these features serve some function or role and how these features have come into existence. As shown in Table 4, from year three onwards, all pre-tests performed at the beginning of each school year will also serve as retention tests for the interventions performed the year before. The main two types of questions are similar to those used in the study reported in this article. These questions will have the form "Why does it have this feature?" and "Is this feature useful for something?" As already explained above, a student who would provide an "In order to" explanation to a "Why?" question and then would describe why the respective feature was useful, would have expressed his teleological intuitions both implicitly and explicitly.

We follow White and Arzi in defining a longitudinal study as " $\ldots$ one in which two or more measures or observations of a comparable form are made of the same individuals or entities over a period of at least one year" (2005, p.138). Such studies have the advantage that a particular group of students can be studied over long periods of time. Longitudinal studies are difficult to conduct, however, contrary to short-term studies, they can uncover how conceptual development related to learning and understanding science occurs. Actual learning takes time, and its outcomes may not be evident in an immediate post-test. Consequently, a longitudinal study that allows the comparison of the same students at various ages may provide a detailed and accurate account of the various factors that affect learning (White and Arzi 2005). Of course, development involves multivariate changes that may not be easy to assess (Ferrer and McArdle 
Table 4 A summary of the research design

\begin{tabular}{|c|c|c|c|c|c|}
\hline & Year 1 & Year 2 & Year 3 & Year 4 & Year 5 \\
\hline Pre-K & PRT & & & & \\
\hline K & PRT-PI & PRT- $\mathrm{I}_{1}-\mathrm{IT}-\mathrm{I}_{2}-\mathrm{PST}$ & & & \\
\hline Grade 1 & PRT-PI & PRT $-\mathrm{I}_{1}-\mathrm{IT}-\mathrm{I}_{2}-\mathrm{PST}$ & PRT- $\mathrm{I}_{1}-\mathrm{IT}-\mathrm{I}_{2}-\mathrm{PST}$ & & \\
\hline Grade 2 & PRT-PI & PRT $-\mathrm{I}_{1}-\mathrm{IT}-\mathrm{I}_{2}-\mathrm{PST}$ & PRT $-\mathrm{I}_{1}-\mathrm{IT}-\mathrm{I}_{2}-\mathrm{PST}$ & PRT- $\mathrm{I}_{1}-\mathrm{IT}-\mathrm{I}_{2}-\mathrm{PST}$ & \\
\hline Grade 3 & PRT-PI & PRT- $\mathrm{I}_{1}-\mathrm{IT}-\mathrm{I}_{2}-\mathrm{PST}$ & PRT $-\mathrm{I}_{1}-\mathrm{IT}-\mathrm{I}_{2}-\mathrm{PST}$ & PRT- $\mathrm{I}_{1}-\mathrm{IT}-\mathrm{I}_{2}-\mathrm{PST}$ & PRT- $\mathrm{I}_{1}-\mathrm{IT}-\mathrm{I}_{2}-\mathrm{PST}$ \\
\hline Grade 4 & PRT-PI & & PRT- $\mathrm{I}_{1}-\mathrm{IT}-\mathrm{I}_{2}-\mathrm{PST}$ & PRT $-\mathrm{I}_{1}-\mathrm{IT}-\mathrm{I}_{2}-\mathrm{PST}$ & PRT $-\mathrm{I}_{1}-\mathrm{IT}-\mathrm{I}_{2}-\mathrm{PST}$ \\
\hline Grade 5 & PRT-PI & & & PRT $-\mathrm{I}_{1}-\mathrm{IT}-\mathrm{I}_{2}-\mathrm{PST}$ & PRT $-\mathrm{I}_{1}-\mathrm{IT}-\mathrm{I}_{2}-\mathrm{PST}$ \\
\hline Grade 6 & PRT-PI & & & & PRT- $\mathrm{I}_{1}-\mathrm{IT}-\mathrm{I}_{2}-\mathrm{PST}$ \\
\hline
\end{tabular}

$P R T$ pre-test, also serves as retention test for the previous grade, $I T$ intermediate test, $P S T$ post-test, $P I$ pilot intervention, $I_{1}$ teaching intervention after the pre-test, $I_{2}$ teaching intervention after the intermediate test and before the post-test

2010), but nevertheless this is the only way to understand how intuitions and biases develop.

For the proposed study, we suggest a true experimental design, according to Campbell and Stanley (1963). Students of each grade will be randomly divided into classes. Approximately $1 / 3$ of them should be the experimental group and approximately $2 / 3$ of them should be the control group. The latter will undergo the "normal" conceptual development, i.e., the development that would take place without any particular teaching intervention that would address students' teleological intuitions. Thus, the study of the explanations given by students of the control group over the course of four years would allow documentation of whether any particular conceptual shifts related to teleology take place during the elementary years. This would provide an outline of the "normal" conceptual development-related to teleology-to which the experimental group will be compared. In this way, the effectiveness of teaching interventions that address teleological intuitions can be properly assessed.

Evans (2008) has concluded that a conceptual shift takes place around eight years old as five to seven year olds provide different explanations for the origin of species compared to eight to ten year olds. This shift is expected to take place in grade three, and the proposed research design will allow the longitudinal study of four consecutive "grade three" groups of students from year two to year five. Moreover, the particular research design will probably allow documentation of whether the particular conceptual shift takes place earlier (in grade two) or later (in grade four). Of course, we anticipate that by performing a pre-test, an intermediate test after the first teaching intervention, and a post-test after the second teaching intervention (see Table 2) it will be possible to document any conceptual shift taking place in any of the grades one to five. Another advantage of the proposed research design, besides the fact that it allows the longitudinal study of four groups for four years that is expected to provide a thorough understanding of the conceptual development related to teleology, is that it also allows comparisons between different groups of students of the same age. Thus, it would be possible to compare two groups of kindergarten students (years one and two), three groups of grade one students (years one to three), four groups of grade two students (years one to four), four groups of grade three students (years two to five), three groups of grade four students (years three to five), and two groups of grade five students (years four to five) (see Table 4). By doing this, it would be possible to know which of the concepts and conceptual shifts documented are representative of students of each age, and consequently characteristic of each age, and which are simply documented in particular groups of students. In short, by studying longitudinally four groups of students for four years, a large number of students of each grade would have been studied, and this would provide an outline of conceptual development based on a large sample.

One important issue is where such a study may be conducted. White and Arzi (2005) note that random selection is rarely possible in educational research, and that usually researchers have to work with whomever they can get. Students should be allocated to classes randomly in order to have balanced groups. Moreover, a longitudinal study requires commitment from the subjects of the research for a long period. Thus, a large group of students is required so that even if some students eventually leave-what Campbell and Stanley (1963) have termed selective mortality - there will be no serious problem for the study. The existence of the control group will help deal with two other problems recognized by Campbell and Stanley as affecting the validity of a study: history and maturation. The term history refers to anything that happens alongside the intervention that might affect the outcome of a study-like a documentary film or a visit to the museum. The term maturation refers to the improvement in students' performance that takes place not because of the intervention but just because they grew up. By performing the same test to both an experimental and a control group simultaneously, we expect to eliminate the 
Table 5 The teaching interventions that will be performed in each grade
Teaching intervention 1

Teaching intervention 2

\begin{tabular}{lll}
\hline $\mathrm{K}$ & Organisms and artifacts & Organisms and natural objects \\
Grade 1 & Invertebrates & Earth, Moon and Sun \\
Grade 2 & Vertebrates (marine mammals) & Plants \\
Grade 3 & Vertebrates (terrestrial mammals) & Earth and planets \\
Grade 4 & Human body & Plants \\
Grade 5 & Animals & Solar system \\
Grade 6 & Adaptation and homology & Plants \\
\hline
\end{tabular}

foregoing factors that might affect the validity of the conclusions.

The teaching interventions that will be performed in the various grades should aim at helping students realize that their teleological explanations do not work in nature. To achieve this, there are two main prerequisites: (1) the abandonment of teleological language and its elimination from any educational material and (2) the proper understanding that organisms are neither perfect, nor designed. If these are done consistently and repeatedly in elementary science instruction, students might realize the error of their initial teleological explanations about organisms are wrong. The abandonment of teleological language during biology instruction in elementary school is a first crucial step. Even in biology textbooks one can find expressions like "Birds have wings for flying." And if a teacher asked "Why do birds have wings?" the most probable answer students would give would be "for flying." We suggest that elementary students can be brought to conflict situations which might help them realize that there are no simple answers to such questions. For example, when students reply that wings are for flying, the teacher could argue that wings are also for swimming, as penguins use them in order to swim and not to fly. The teacher could also remind students that ostriches neither fly nor swim and still possess wings. Such examples might drive students to reconsider their own ideas. It is important for teachers to make their students understand that a "Why?" question differs significantly from a "What for?" question. The "What for?" question presupposes that a purpose exists and thus the question requires a teleological explanation. The "Why?" question is free from this assumption, although it can be given a teleological explanation as well. Hence, teachers should not tell their students that "Birds have wings for flying" but that "Birds fly because they have wings." Airplanes have wings for flying; but contrary to birds, airplanes are artifacts intentionally designed for this purpose.

A second crucial step would be to help elementary students understand that organisms often lack features which are necessary for their survival. Thus, while one could claim that whales have their hydrodynamic shapes in order to swim fast in the sea, he could not explain why they do not also have gills which unquestionably are useful for underwater breathing. It is more appropriate to say that "Whales swim fast in the sea because they have a hydrodynamic shape." But it is also the case that whales have to swim up to the surface in order to breathe and that "Whales do not have gills in order to be able to swim underwater" as many species that live in the sea do. It is important that students realize that in many cases and aspects organisms are not perfect. Biology instruction should not only focus on useful features but also on useless or even disadvantageous ones. These reflect the evolutionary past of the various species; and new species emerge from natural processes of change. New species evolve from preexisting ones and are not formed anew. Consequently, they preserve features of their ancestors, no matter if these are useful or not. Evolutionary history is important for understanding the origin of features (Kampourakis 2011).

In Table 5, we present an overview of possible teaching interventions. These interventions will involve only those students belonging to the experimental group. It should be noted that students should not only study examples of animals but also of plants. In addition, examples from astronomy (planets and solar system) would be useful as well since students also tend to provide teleological explanations about the properties of planetary bodies.

To summarize, the proposed research may make some useful contributions. First, the teaching of evolution, a crucial issue in science education, is addressed from a different (developmental-psychological and not political) perspective, with a focus on a different age group than usual (elementary rather than secondary or post-secondary). In addition, elementary students' preconceptions (those related to teleology in particular and not about evolution in general) will be documented and will serve as the basis for the design of specific teaching interventions that will aim to challenge them. Possible conceptual shifts related to teleology that elementary students undergo spontaneously in the normal course of development may be documented during a study of a kind that has never been performed in the past: four groups of students of different Grades will be studied simultaneously and longitudinally for four years. The possibility of promoting instruction-based conceptual change related to 
teleology will also be investigated by studying an experimental group and comparing it to the control group of the same age, attending the same grades at the same time.

With the proposed research program, a new perspective will be added to the evolution debates. People who oppose evolution may reject it not only because they feel that it is incompatible with their worldviews but also because they do not understand it. The perceived conflict may not only be between evolution and religious views but also between evolution and their teleological view of nature. The proposed research programme may also provide a framework for challenging children's teleological intuitions during elementary school. This might provide fertile ground for evolution instruction in secondary and post-secondary settings, but it will not be investigated in the proposed research project. However, if it were shown that children's teleological intuitions can be effectively challenged at some particular age in their conceptual development, policy makers and curriculum developers should reconsider how evolution is currently taught in schools.

\section{References}

Aldridge M, Dingwall R. Teleology on television? Implicit models of evolution in broadcast wildlife and nature programmes. Eur J Commun. 2003;18(4):435-53.

Ariew A. Ernst Mayr's 'ultimate/proximate' distinction reconsidered and reconstructed. Biol Philos. 2003;18:553-65.

Ariew A. Teleology. In: Hull D, Ruse M, editors. Cambridge companion to the philosophy of biology. Cambridge: Cambridge University Press; 2007. p. 160-81.

Audi R. Religion and the politics of science: can evolutionary biology be religiously neutral? Philosophy and Social Criticism. 2009;35 (1-2), 23-50.

Bar V, Zinn B, Goldmuntz R, Sneider C. Children's concepts about weight and free fall. Sci Educ. 1994;78(2):149-69.

Bloom P, Weisberg DS. Childhood origins of adult resistance to science. Science. 2007;316:996-7.

Branch G, Scott EC. The latest face of Creationism. Sci Am. 2009;300 (1):92-9.

Campbell DT, Stanley J. Experimental and quasi-experimental designs forresearch. Boston: Houghton-Mifflin; 1963.

Carey S. Conceptual change in childhood. Cambridge, Massachussetts and London, England: MIT Press; 1985.

Carey S. Science education as conceptual change. J Appl Dev Psychol. 2000;21:13-9.

Chanet B, Lusignan F. Teaching evolution in primary schools: an example in French classrooms. Evol Educ Outreach. 2009;2:136-40.

Curry A. Creationist beliefs persist in Europe. Science. 2009;323:1159.

Darwin C. On the origin of species by means of natural selection. London: John Murray; 1859.

DiYanni C, Kelemen D. Time to get a new mountain? The role of function in children's conceptions of natural kinds. Cognition. 2005;97:325-35.

Evans EM. Conceptual change and evolutionary biology: a developmental analysis. In: Vosniadou S, editor. International Handbook of Research on Conceptual Change. Routledge: New York; 2008. p. 263-94.

Ferrer E, McArdle JJ. Longitudinal modeling of developmental changes in psychological research. Curr Dir Psychol Sci. 2010;19(3):149-54.
Goldberg RF, Thompson-Schill SL. Developmental "roots" in mature biological knowledge. Psychol Sci. 2009;20(4):480-7.

González Galli LM, Meinardi EN. The role of teleological thinking in learning the Darwinian model of evolution. Evol Educ Outreach. 2011;4:145-52.

Graebsch A, Schiermeier Q. Anti-evolutionists raise their profile in Europe. Nature. 2006;444:406-7.

Greif M, Kemler-Nelson D, Keil FC, Guiterrez F. What do children want to know about animals and artifacts?: domainspecific requests for information. Psychol Sci. 2006;17 (6):455-9.

Hameed S. Bracing for Islamic Creationism. Science. 2008;322:1637.

Harrison AG, Grayson DJ, Treagust DF. Investigating a first-grade1 student's evolving conceptions of heat and temperature. J Res Sci Teach. 1999;36(1):55-87.

Hermann RS. Breaking the cycle of continued evolution education controversy: on the need to strengthen elementary level teaching of evolution. Evol Educ Outreach. 2011;4(2):267-74.

Huxley J. Evolution: the modern synthesis. London: Allen \& Unwin; 1942.

Inagaki K, Hatano G. Young children's naive thinking about the biological world. New York: Psychology Press; 2002.

Kampourakis K, Zogza V. Students' preconceptions about evolution: how accurate is the characterization as "Lamarckian" when considering the history of evolutionary thought? Sci Educ. 2007;16 (3-5):393-422.

Kampourakis K, Zogza V. Students' intuitive explanations of the causes of homologies and adaptations. Sci Educ. 2008;17(1): 27-47

Kampourakis K. Teaching about adaptation: Why evolutionary history matters. Sci Educ. 2011. doi:10.1007/s11191-011-9363-2

Kampourakis K, Pavlidi V, Papadopoulou M, Palaiokrassa E. Children's teleological intuitions: what kind of explanations do 7-8 year olds give for the features of organisms, artifacts and natural objects? Res Sci Educ. 2011. doi:10.1007/ s11165-011-9219-4

Keil FC. The origins of an autonomous biology. In: Gunnar MR, Maratsos M, editors. Modularity and constraints in language and cognition. Minnesota Symposium on Child Psychology, vol. 25. Hillsdale, New Jersey: Erlbaum; 1992. p. 103-38.

Keil FC. The birth and nurturance concepts by domains: the origins of concepts of living things. In: Hirschfeld LA, Gelman S, editors. Mapping the mind: domain specificity in cognition and culture. Cambridge: Cambridge University; 1994. p. 234-54.

Kelemen D. Function, goals and intention: children's teleological reasoning about objects. Trends Cogn Sci. 1999a;3(12):461-8.

Kelemen D. The scope of teleological thinking in preschool children. Cognition. 1999b;70:241-72.

Kelemen D. Why are rocks pointy? Children's preference for teleological explanations of the natural world. Dev Psychol. 1999c;35:1440-52.

Kelemen D, Rosset E. The human function compunction: teleological explanation in adults. Cognition. 2009;111:138-43.

Mayr E. Cause and effect in biology. Science. 1961;134:1501-1506.

Miller JD, Scott EC, Okamoto S. Public acceptance of evolution. Science. 2006;313(5788):765-6.

Numbers R. The Creationists: from Scientific Creationism to Intelligent Design. Cambridge Massachusetts: Harvard University Press; 2006.

Numbers R. That Creationism is a uniquely American phenomenon. In: Numbers R, editor. Galileo goes to jail, and other myths about science and religion. Cambridge Massachusetts: Harvard University Press; 2009. p. 215-23.

Pigliucci M, Muller G, editors. Evolution: the extended synthesis. Cambridge, MA: MIT Press; 2010.

Smith MU. Current status of research in teaching and learning evolution: II. pedagogical issues. Sci Educ. 2010;19(6-8):539-71.

Sober E. What is wrong with Intelligent Design? Q Rev Biol. 2007;82 (1):3-8. 
Southerland SA, Abrams E, Cummins CL, Anselmo J. Understanding students' explanations of biological phenomena: conceptual frameworks or p-prims? Sci Educ. 2001;85:32848.

Springer K. How a naive theory of biology is acquired. In: Siegal M, Peterson C, editors. Children's understanding of biology and health. Cambridge Series in Perceptual and Cognitive Development. Cambridge: Cambridge University Press; 1999.
Taber KS, Watts M. The secret life of the chemical bond: students' anthropomorphic and animistic references to bonding. Int J Sci Educ. 1996;18(5):557-68.

Talanquer V. Explanations and teleology in chemistry education. Int J Sci Educ. 2007;29(7):853-70.

Walsh D. Teleology. In: Ruse M, editor. The Oxford handbook of philosophy of biology. Oxford: Oxford University Press; 2008. p. 113-37.

White RT, Arzi HJ. Longitudinal studies: designs, validity, practicality, and value. Res Sci Educ. 2005;35(1):137-49. 